\title{
ADDITIONS TO THE VASCULAR PLANT FLORA OF THE REPUBLIC OF MORDOVIA (RUSSIA): CONTRIBUTION OF THE INATURALIST PLATFORM
}

\author{
Anatoliy A. KHAPUGIN ${ }^{1,2}$, Tatyana B. SILAEVA ${ }^{3}$, Ekaterina S. FEDASHEVA ${ }^{3}$, \\ Maria A. TYAPUKHINA ${ }^{3}$, Angelina S. GURYANOVA ${ }^{3}$, Vasilisa I. SHLYAPKINA ${ }^{3}$, \\ Irina G. ESINA ${ }^{1}$, Anastasia N. KOCHETKOVA, Darya A. KONUSOVA ${ }^{3}$, \\ Natalya S. MUKLETSOVA ${ }^{3}$, Elena S. PANKOVA ${ }^{3}$, Alena A. TIMOFEEVA \\ ${ }^{1}$ Joint Directorate of the Mordovia State Nature Reserve and National Park "Smolny", Russia \\ ${ }^{2}$ Tyumen State University, Russia \\ ${ }^{3}$ Mordovia State University, Russia \\ e-mail: hapugin88@yandex.ru
}

\begin{abstract}
The (re)check of the iNaturalist data related to the Republic of Mordovia (European Russia) allowed us to find 16 vascular plant species, considered to be new taxa for the vascular plant flora of this region, in comparison to Silaeva et al. (2010). These species are Nonea rossica, Erigeron strigosus, Medicago $\times$ varia, Dianthus chinensis, Symphytum $\times$ uplandicum, Lamprocapnos spectabilis, Petunia $\times$ atkinsiana, Oenothera villosa, Parthenocissus inserta, Reynoutria $\times$ bohemica, Eschscholzia californica, Quercus rubra, Digitaria sanguinalis, Lysimachia punctata, Acer ginnala and Stachys byzantina. In addition, we present new data about the distribution of the five species (Silene wolgensis, Amaranthus cruentus, Cruciata laevipes, Euphorbia cyparissias and Achillea leptophylla) found in the Republic of Mordovia since publication of Silaeva et al. (2010). A majority of the species under discussion are alien plants arrived in Mordovia accidentally or considered as cultivated plants escaping in the wild. Taking into account the newly revealed species, the vascular plant flora of the Republic of Mordovia currently includes 1464 species. In this study, we highlight again the relevance and feasibility of the use of the iNaturalist platform, as an effective tool for the study and monitoring of regional and national biodiversity.
\end{abstract}

Keywords: alien species, biogeography, citizen science, cultivated species, European Russia, new species.

\section{Introduction}

The study of plant biodiversity is an important part of biological and ecological research around the world $[2,8,14,24]$. The additions to data on the plant diversity of certain regions or Protected Areas [1, 3, 5, 28] are a basis for creation of checklists of countries and particular geographical macro-regions. This is especially important in relation to such a large country as Russia, characterized by broad and at the same time hard-to-reach territories. Under conditions of limited knowledge about the biodiversity in the study area, the possibility to find new species for this area becomes higher even with limited research efforts, e.g. [4].

In contrary to most Russian regions, the Republic of Mordovia is characterized by the highlevel knowledge of the vascular plant flora in the region, including its Protected Areas, namely Mordovia State Nature Reserve and National Park "Smolny". Recently, the checklists of the vascular plant flora of the whole Mordovia [19], National Park "Smolny" [20] and Mordovia State Nature Reserve [26] have been published. Later additions to these checklists have also appeared 
$[12,22,23]$. Taking them into account, up until now the vascular plant flora of the Republic of Mordovia consisted of 1448 species.

To study plant diversity, traditionally the experience and research data of graduate botanical specialists are applied. Nevertheless, in recent years the use of citizen science data has become increasingly widespread both in Russia and, more especially, worldwide. In Russia, the platform iNaturalist is the most widespread tool for the study of the national vascular plant diversity. On the basis of this tool, Alexey P. Seregin created and is managing the iNaturalist project "Flora of Russia" [17, 18]. In addition, it was demonstrated that joint coordinated partnering of citizen scientists (non-professionals, amateurs) and researchers (incl. publications, herbarium data, etc.) is the most effective way to reveal biodiversity [9].

The present paper aims to analyze and generalize the modern data about vascular plant observations using the regional iNaturalist project "Flora of Mordovia" in order to find species newly mentioned for the flora of the Republic of Mordovia.

\section{Material and Methods}

The Republic of Mordovia is located on the margin of the forest and forest-steppe natural zones in the centre of European Russia. The region covers about $26200 \mathrm{~km}^{2}$. Eastern Mordovia is located on the north-western spurs of the Volga Upland, while the Oka-Don Lowland covers the western part of the region. The Republic of Mordovia is characterized by high habitat diversity. Coniferous and mixed (coniferous-deciduous) forests are situated predominantly in the western and north-western parts of Mordovia. Broadleaved forests are located in the centre and east of the region. The forest-steppe landscapes dominate in the eastern and south-eastern areas of the Republic of Mordovia [29]. Water bodies of Mordovia are inhabited by 163 species and nine hybrids from 74 genera and 39 families [19, 27]. Mires cover about $5 \%$ of the region's area, which is reflected in the high Sphagnum species diversity [6]. At the same time, data on the diversity of lichens, macrofungi and bryophytes are known only for the National Park "Smolny" and the Mordovia State Nature Reserve, which is not enough to judge their diversity in the whole Republic of Mordovia.

Since 2008, the platform iNaturalist (https://www.inaturalist.org/) has been an online tool to identify the observations of organisms recorded by amateurs and naturalists. The main task of iNaturalist tool is a biodiversity registration using a set of separate observations. There are a number of publications (e.g. $[9,15,16]$ ) devoted to the new records of organisms of various taxonomic groups made by amateur naturalists around the world. The iNaturalist project "Flora of Russia" has been founded in January 2019 by Moscow University team of researchers [17]. To date, the number of Research Grade observations has increased considerably, reaching 750000 Research Grade observations of vascular plants by 9 September 2020 [18].

By 4 November 2020, the regional iNaturalist project "Flora of Mordovia" consisted of 17825 Research Grade observations and 867 species. By this time, we checked the entire set of observations in comparison to the most relevant publication about the vascular plant flora of the Republic of Mordovia [19]. During this process, a number of observations, previously recognized as Research Grade, have been re-defined due to incorrect initial identification. As a result, their status was downgraded. The most active iNaturalist observers who found species new to the 
Mordovian flora are the authors of the present paper.

The scientific names of plant species are used in accordance with taxonomy used on the iNaturalist platform. Each vascular plant species is attributed by family (according to [13]), list of iNaturalist Research Grade observations and notes. For each location, we present the following information: country, Russian region, municipal district of the region, geographical coordinates, date of observation, name of the observer or (if unknown) author ID on the iNaturalist platform, and finally URL-link of the observation on iNaturalist platform. Currently, some of the present observations were exported to the database Global Biodiversity Information Facility (GBIF) [25]. In our paper, we have deliberately used the iNaturalist data (instead of database-aggregator GBIF), because it is the primary data source for the observations presented.

\section{Results and Discussion}

Erigeron strigosus Muhl. ex Willd. (incl. Erigeron strigosus var. septentrionalis (Fernald $\&$ Wiegand) Fernald) (Asteraceae)

Locations: 1) Russia, Republic of Mordovia, Atyashevo district, $54.636181^{\circ} \mathrm{N}, 45.852979^{\circ} \mathrm{E}$, Author ID: nat_boriskina, 05.08.2020, iNaturalist-observation: https://www.inaturalist.org/observations/57116341; 2) Russia, Republic of Mordovia, Zubova Polyana district, $54.283069^{\circ}$ N, $42.849648^{\circ}$ E, I.G. Esina, 30.08.2020, iNaturalistobservation: https://www.inaturalist.org/observations/58016502; 3) Russia, Republic of Mordovia, Ichalki district, $54.748177^{\circ} \mathrm{N}, \quad 45.242866^{\circ} \mathrm{E}$, Author ID: andrey_rodyushkin, 04.07.2020, iNaturalist-observation: https://www.inaturalist.org/observations/52060351; 4) Russia, Republic of Mordovia, Ichalki district, $54.639170^{\circ} \mathrm{N}$, $45.454661^{\circ} \mathrm{E}, \quad$ E.S. $\quad$ Pankova, 05.07.2020, iNaturalist-observation: https://www.inaturalist.org/observations/51993164; 5) Russia, Republic of Mordovia, Ichalki district, $54.728273^{\circ} \mathrm{N}$, $45.121669^{\circ} \mathrm{E}$ Author $\quad$ ID: $\quad$ doshirak, 28.06.2020, iNaturalist-observation: https://www.inaturalist.org/observations/51667938; 6) Russia, Republic of Mordovia, Ichalki district, $54.726142^{\circ} \mathrm{N}$, $45.290776^{\circ} \mathrm{E}, \quad$ Author $\quad$ ID: larinaalina, 01.07.2020, iNaturalist-observation: https://www.inaturalist.org/observations/51559838; 7) Russia, Republic of Mordovia, Ichalki district, $54.877670^{\circ} \mathrm{N}$, 45.477700 E, $\quad$ A.A. $\quad$ Khapugin, 25.07.2015, iNaturalist-observation: https://www.inaturalist.org/observations/38802074; 8) Russia, Republic of Mordovia, Kovylkino district, $54.032493^{\circ} \mathrm{N}, \quad 43.916270^{\circ} \mathrm{E}$, Author ID: mkrivtsova, 03.07.2020, iNaturalist-observation: https://www.inaturalist.org/observations/51782051; 9) Russia, Republic of Mordovia, Kovylkino district, $54.100525^{\circ} \mathrm{N}, \quad 43.894539^{\circ} \mathrm{E}$, Author ID: maria_99, 07.07.2020, iNaturalist-observation: https://www.inaturalist.org/observations/52384414; 10) Russia, Republic of Mordovia, Krasnoslobodsk district, $54.344707^{\circ} \mathrm{N}, \quad 44.28089^{\circ} \mathrm{E}$, Author ID: rejoin, 06.08.2009, iNaturalist-observation: https://www.inaturalist.org/observations/20730229; 11) Russia, Republic of Mordovia, Temnikov district, $54.843296^{\circ} \mathrm{N}, \quad \quad \quad 43.183097^{\circ} \mathrm{E}, \quad$ I.G. $\quad$ Esina, $12.09 .2020, \quad$ iNaturalist-observation: https://www.inaturalist.org/observations/59294604; 12) Russia, Republic of Mordovia, Temnikov district, $54.698881^{\circ} \mathrm{N}, \quad 43.410678^{\circ} \mathrm{E}, \quad$ I.G. $\quad$ Esina, 24.08.2020, iNaturalist-observation: https://www.inaturalist.org/observations/57422597; 13) Russia, Republic of Mordovia, Temnikov district, $54.661360^{\circ} \mathrm{N}, \quad 43.130810^{\circ} \mathrm{E}, \quad$ I.G. $\quad$ Esina, 27.07.2020, iNaturalist-observation: https://www.inaturalist.org/observations/54819408; 14) Russia, Republic of Mordovia, Temnikov district, $54.704926^{\circ} \mathrm{N}, \quad 43.240315^{\circ} \mathrm{E}$, Author ID: entomokot, 20.07.2020, iNaturalist-observation: https://www.inaturalist.org/observations/53719478; 15) Russia, Republic of Mordovia, Tengushevo district, $54.545475^{\circ} \mathrm{N}, \quad 42.909772^{\circ} \mathrm{E}, \quad$ I.G. $\quad$ Esina, $30.08 .2020, \quad$ iNaturalist-observation: https://www.inaturalist.org/observations/58008926; 16) Russia, Republic of Mordovia, Tengushevo district, $54.760834^{\circ} \mathrm{N}, \quad 42.699169^{\circ} \mathrm{E}, \quad$ N.S. $\quad$ Mukletsova, 10.07 .2020 , iNaturalist-observation: https://www.inaturalist.org/observations/52550383; 17) Russia, Republic of Mordovia, Tengushevo district, $54.772735^{\circ} \mathrm{N}, \quad 42.717056^{\circ} \mathrm{E}$, Author ID: valentina999, 08.07.2020, iNaturalist-observation: https://www.inaturalist.org/observations/52342677; 18) Russia, Republic of Mordovia, Tengushevo district, $54.736066^{\circ} \mathrm{N}, \quad 42.777343^{\circ} \mathrm{E}$, Author ID: aleksandra_a, 04.07.2020, iNaturalist-observation: https://www.inaturalist.org/observations/51885185; 19) Russia, Republic of Mordovia, Tengushevo district, 
$54.669737^{\circ} \mathrm{N}, \quad 42.829800^{\circ} \mathrm{E}, \quad$ Author ID: aleksandra_a, 02.07.2020, iNaturalist-observation: https://www.inaturalist.org/observations/51677788; 20) Russia, Republic of Mordovia, Chamzinka district, $54.369124^{\circ} \mathrm{N}, \quad 45.709299^{\circ} \mathrm{E}, \quad$ A.S. $\quad$ Guryanova, 25.06.2020, iNaturalist-observation: https://www.inaturalist.org/observations/50866076; 21) Russia, Republic of Mordovia, Saransk urban district, $54.191003^{\circ} \mathrm{N}, \quad 45.206582^{\circ} \mathrm{E}$, Author ID: vasiliyevamasha, 30.06.2020, iNaturalist-observation: https://www.inaturalist.org/observations/51452159; 22) Russia, Republic of Mordovia, Saransk urban district, $54.209263^{\circ} \mathrm{N}, \quad 45.131133^{\circ} \mathrm{E}$, Author ID: alinasitkina, 06.08.2020, iNaturalist-observation: https://www.inaturalist.org/observations/55713557; 23) Russia, Republic of Mordovia, Saransk urban district, $54.213478^{\circ} \mathrm{N}, \quad 45.198648^{\circ} \mathrm{E}, \quad$ E.S. Fedasheva, 13.07.2020, iNaturalist-observation: https://www.inaturalist.org/observations/52927172; 24) Russia, Republic of Mordovia, Saransk urban district, $54.151675^{\circ} \mathrm{N}, \quad 45.189028^{\circ} \mathrm{E}, \quad$ E.S. $\quad$ Fedasheva, 11.07.2020, iNaturalist-observation: https://www.inaturalist.org/observations/52663073; 25) Russia, Republic of Mordovia, Saransk urban district, $54.159808^{\circ} \mathrm{N}, \quad 45.133348^{\circ} \mathrm{E}, \quad$ V.I. Shlyapkina, 11.07.2020, iNaturalist-observation: https://www.inaturalist.org/observations/52651980; 26) Russia, Republic of Mordovia, Saransk urban district, $54.165825^{\circ} \mathrm{N}, \quad 45.140836^{\circ} \mathrm{E}$, Author ID: naturalist38035, 08.07.2020, iNaturalist-observation: https://www.inaturalist.org/observations/52349795; 27) Russia, Republic of Mordovia, Saransk urban district, $54.185015^{\circ} \mathrm{N}, \quad 45.208185^{\circ} \mathrm{E}, \quad$ E.S. $\quad$ Fedasheva, 01.07.2020, iNaturalist-observation: https://www.inaturalist.org/observations/51580177.

Note: According to Silaeva et al. (2010) [19], E. strigosus is considered as a synonym of E. annuus L. However, at the present time, E. strigosus and E. annuus are recognized as two separate species [e.g. 11, 13]. Thus, E. strigosus (incl. E. strigosus var. septentrionalis) is known in Atyashevo, Zubova Polyana, Ichalki (incl. National Park "Smolny"), Kovylkino, Krasnoslobodsk, Temnikov, Tengushevo and Chamzinka districts and Saransk urban district. In future, we suggest revision of all the E. annuus locations published in Silaeva et al. (2010) [19], in order to clarify the distribution of both species in the Republic of Mordovia. In addition, the indicated iNaturalist observations should be clarified using herbarium specimens. We suppose that a similar situation with regard to the need to distinguish Erigeron annuus and E. strigosus exists in other parts of Eurasia.

\section{Nonea rossica Steven. (Boraginaceae)}

Locations: 1) Russia, Republic of Mordovia, Atyashevo district, $54.587730^{\circ} \mathrm{N}, 46.087881^{\circ} \mathrm{E}$, Author ID: somova_ksenia, 05.08.2020, iNaturalist-observation: https://www.inaturalist.org/observations/55480210; 2) Russia, Republic of Mordovia, Torbeevo district, $54.162913^{\circ} \mathrm{N}, 43.114874^{\circ} \mathrm{E}$, Author ID: sea_tea_sea, 07.06.2020, iNaturalist-observation: https://www.inaturalist.org/observations/48806128.

Note: This is the second Nonea species (besides N. pulla (L.) DC.) in Mordovia, which is possibly located at the edge of the natural ranges of these species [13]. On the other hand, $N$. rossica could be a more correct name of plants previously recognized as $N$. pulla, for which $N$. rossica has been considered as a synonym [19].

\section{Acer ginnala Maxim. (Sapindaceae)}

Locations: 1) Russia, Republic of Mordovia, Saransk urban district, $54.190447^{\circ} \mathrm{N}, 45.124805^{\circ} \mathrm{E}$, Author ID: obruchnikova99, 14.06.2020, iNaturalist-observation: https://www.inaturalist.org/observations/49704352.

Note: This species is mentioned for the first time in the Republic of Mordovia outside of cultivation. The checklist of the vascular flora [19] indicated this species only as a cultivated plant. In future, its escaping into the wild and further dispersal is possible in the Botanical Garden of the Mordovia State University. 


\section{Dianthus chinensis L. (Caryophyllaceae)}

Locations: 1) Russia, Republic of Mordovia, Ichalki district, $54.664993^{\circ} \mathrm{N}, 45.660258^{\circ}$ E, A.S. Guryanova, 21.06.2020, iNaturalist-observation: https://www.inaturalist.org/observations/50392542.

Note: This location in Ichalki district is the first record of this species outside cultivation in the Republic of Mordovia. Previously, D. chinensis was noted in the region only under cultivated conditions [19].

\section{Digitaria sanguinalis (L.) Scop. (Poaceae)}

Locations: 1) Russia, Republic of Mordovia, Saransk urban district, $54.210273^{\circ}$ N, $45.204474^{\circ}$ E, T.B. Silaeva, 07.09.2020, iNaturalist-observation: https://www.inaturalist.org/observations/58836621.

Note: This record in the Saransk urban district is the first location in Mordovia. Silaeva et al. (2010) [19] noted that in Maevskiy (2006) [10] this species was mentioned mistakenly due to a lack of reliable data. In future, new records of $D$. sanguinalis are possible in disturbed habitats.

\section{Eschscholzia californica Cham. (Papaveraceae)}

Locations: 1) Russia, Republic of Mordovia, Saransk urban district, 54.213940 ${ }^{\circ}$ N, 45.125023 E, Author ID: vadyaeva_irina, 08.07.2020, iNaturalist-observation: https://www.inaturalist.org/observations/52389421; 2) Russia, Republic of Mordovia, Bolshie Berezniki district, 54.175538 N, $45.945891^{\circ}$ E, Author ID: yaroslav_otryaskin, 23.06.2020, iNaturalist-observation: https://www.inaturalist.org/observations/50652476.

Note: This is the first record of this alien species in the Republic of Mordovia outside cultivation. According to Silaeva et al. (2010) [19], E. californica was indicated only in cultivation.

\section{Lamprocapnos spectabilis (L.) Fukuhara (Papaveraceae)}

Locations: 1) Russia, Republic of Mordovia, Ichalki district, $54.699770^{\circ} \mathrm{N}, 45.24876^{\circ}$ E, M.A. Tyapukhina, 11.06.2020, iNaturalist-observation: https://www.inaturalist.org/observations/49809490.

Note: This is the first record of L. spectabilis outside cultivation in Mordovia [19]. Due to its attractive appearance, this alien species is likely to be found in other locations in the region.

\section{Lysimachia punctata L. (Primulaceae)}

Locations: 1) Russia, Republic of Mordovia, Saransk urban district, $54.200459^{\circ} \mathrm{N}, 45.111466^{\circ} \mathrm{E}$, Author ID: golub, 08.07.2020, iNaturalist-observation: https://www.inaturalist.org/observations/52370202.

Note: This species is widely cultivated in lawns, flower-gardens and backyards as a decorative ornamental plan, although it was not mentioned in Silaeva et al. (2010) [19]. New records of L. punctata are possible outside cultivation in abandoned backyards and other disturbed habitats.

\section{Medicago $\times$ varia Martyn (Fabaceae)}

Locations: 1) Russia, Republic of Mordovia, Ichalki district, $54.580000^{\circ} \mathrm{N}, 45.097111^{\circ} \mathrm{E}$, D.A. Konusova, 30.06.2020, iNaturalist-observation: https://www.inaturalist.org/observations/51528773; 2) Russia, Republic of Mordovia, Ichalki district, $54.689595^{\circ} \mathrm{N}, 45.224138^{\circ} \mathrm{E}$, M.A. Tyapukhina, 11.07.2020, iNaturalist-observation: https://www.inaturalist.org/observations/52673359; 3) Russia, Republic of Mordovia, Atyashevo district, $54.590556^{\circ} \mathrm{N}, \quad 46.074167^{\circ} \mathrm{E}, \quad$ A.N. Kochetkova, 01.07.2020, iNaturalist-observation: https://www.inaturalist.org/observations/51567478; 4) Russia, Republic of Mordovia, Ruzaevka district, $53.987795^{\circ} \mathrm{N}, \quad 44.623703^{\circ} \mathrm{E}$, Author ID: alena01, 30.06.2020, iNaturalist-observation: https://www.inaturalist.org/observations/51452057; 5) Russia, Republic of Mordovia, Ruzaevka district, $53.931697^{\circ} \mathrm{N}, \quad 44.753423^{\circ} \mathrm{E}, \quad$ A.A. $\quad$ Timofeeva, $16.07 .2020, \quad$ iNaturalist-observation: https://www.inaturalist.org/observations/53472513; 6) Russia, Republic of Mordovia, Temnikov district, $54.894887^{\circ} \mathrm{N}, 43.602554^{\circ} \mathrm{E}$, Author ID: entomokot, 10.07.2020, iNaturalist-observation: 


\section{A.A. KHAPUGIN, T.B. SILAEVA, E.S. FEDASHEVA, M.A. TYAPUKHINA, A.S. GURYANOVA, V.I. SHLYAPKINA, I.G. ESINA, A.N. KOCHETKOVA, D.A. KONUSOVA, N.S. MUKLETSOVA, E.S. PANKOVA, A.A. TIMOFEEVA}

https://www.inaturalist.org/observations/53286844; 7) Russia, Republic of Mordovia, Tengushevo district, $54.780839^{\circ} \mathrm{N}, \quad 42.683396^{\circ} \mathrm{E}$, Author ID: aleksandra_a, 03.07.2020, iNaturalist-observation: https://www.inaturalist.org/observations/51791933; 8) Russia, Republic of Mordovia, Saransk urban district, $54.143071^{\circ} \mathrm{N}, \quad 45.139857^{\circ} \mathrm{E}$, Author ID: olga_ignatyeva_206, 24.06.2020, iNaturalist-observation: https://www.inaturalist.org/observations/50809784; 9) Russia, Republic of Mordovia, Saransk urban district, $54.118859^{\circ} \mathrm{N}, \quad 45.159414^{\circ} \mathrm{E}, \quad$ E.S. $\quad$ Fedasheva, 23.09.2020, iNaturalist-observation: https://www.inaturalist.org/observations/60605846; 10) Russia, Republic of Mordovia, Saransk urban district, $54.199550^{\circ} \mathrm{N}, \quad 45.325280^{\circ} \mathrm{E}$, Author ID: regina_kadikina, 29.08.2020, iNaturalist-observation: https://www.inaturalist.org/observations/57903178; 11) Russia, Republic of Mordovia, Saransk urban district, $54.234341^{\circ} \mathrm{N}, \quad 45.265182^{\circ} \mathrm{E}$, Author ID: vadyaeva_irina, 15.07.2020, iNaturalist-observation: https://www.inaturalist.org/observations/53131028; 10) Russia, Republic of Mordovia, Saransk urban district, $54.152848^{\circ} \mathrm{N}, \quad 45.238114^{\circ} \mathrm{E}$, Author ID: vasiliyevamasha, 04.07.2020, iNaturalist-observation: https://www.inaturalist.org/observations/51890419.

Note: This hybrid has been mentioned in Silaeva et al. (2010) [19] outside the main enumeration as a plant known in Mordovia only in cultivation. Taking into account our records, M. $\times$ varia is known currently outside cultivated places in the Saransk urban district and in Atyashevo, Ichalki, Ruzaevka, Temnikov and Tengushevo districts.

\section{Oenothera villosa Thunb. (Onagraceae)}

Locations: 1) Russia, Republic of Mordovia, Saransk urban district, $54.210417^{\circ} \mathrm{N}, 45.206839^{\circ}$ E, T.B. Silaeva, 07.09.2020, iNaturalist-observation: https://www.inaturalist.org/observations/58850275; 2) Russia, Republic of Mordovia, Saransk urban district, $54.131639^{\circ} \mathrm{N}, 45.141241^{\circ}$ E, T.B. Silaeva, 26.09.2020, iNaturalist-observation: https://www.inaturalist.org/observations/60872539; 3) Russia, Republic of Mordovia, Saransk urban district, $54.127425^{\circ} \mathrm{N}, \quad 45.137386^{\circ} \mathrm{E}, \quad$ T.B. $\quad$ Silaeva, 26.09.2020, iNaturalist-observation: https://www.inaturalist.org/observations/60872507; 4) Russia, Republic of Mordovia, Lyambir district, $54.317951^{\circ} \mathrm{N}$, $45.243953^{\circ} \mathrm{E}, \quad$ A.A. Khapugin, 30.06.2013, iNaturalist-observation: https://www.inaturalist.org/observations/40017945; 5) Russia, Republic of Mordovia, Lyambir district, $54.329673^{\circ} \mathrm{N}$, $45.245885^{\circ} \mathrm{E}, \quad$ A.A. Khapugin, $\quad 15.09 .2013, \quad$ iNaturalist-observation: https://www.inaturalist.org/observations/39929287.

Note: This species is indicated for the first time in Mordovia from the Saransk urban district and Lyambir district [19]. We suggest further searches and study of Oenothera species diversity in the Republic of Mordovia.

\section{Parthenocissus inserta (A.Kern.) Fritsch (Vitaceae)}

Locations: 1) Russia, Republic of Mordovia, Saransk urban district, 54.167232 ${ }^{\circ} \mathrm{N}, 45.113804^{\circ} \mathrm{E}$, Author ID: olga_ignatyeva_206, 22.06.2020, iNaturalist-observation: https://www.inaturalist.org/observations/50571412; 2) Russia, Republic of Mordovia, Saransk urban district, 54.161790 N, 45.191653 E, E.S. Fedasheva, 08.09.2020, iNaturalist-observation: https:/www.inaturalist.org/observations/58969990; 3) Russia, Republic of Mordovia, Saransk urban district, 54.170431 ${ }^{\circ} \mathrm{N}, 45.144171^{\circ} \mathrm{E}$, Author ID: shchelk, 24.07.2020, iNaturalist-observation: https://www.inaturalist.org/observations/54144147.

Note: This the first mention of this alien species in Mordovia, from the Saransk urban district. Previously, Silaeva et al. (2010) [19] noted the possibility of its being recorded outside cultivated places. But until now we had no reliable data for this statement.

\section{Petunia $\times$ atkinsiana (Sweet) D.Don ex W.H.Baxter (Solanaceae)}

Locations: 1) Russia, Republic of Mordovia, Ruzaevka district, 54.129970 ${ }^{\circ}$ N, $45.136655^{\circ}$ E, T.B. Silaeva, 26.09.2020, iNaturalist-observation: https://www.inaturalist.org/observations/60872602. 
Note: Previously, this alien ornamental plant was known from the Republic of Mordovia only in cultivation [19]. The find in Ruzaevka district is the first confirmation of the species occurring in the wild, while we expect new records outside cultivation in future.

\section{Quercus rubra L. (Fagaceae)}

Locations: 1) Russia, Republic of Mordovia, Saransk urban district, $54.174997^{\circ}$ N, $45.276417^{\circ}$ E, V.I. Shlyapkina, 14.07.2020, iNaturalist-observation: https://www.inaturalist.org/observations/53026611.

Note: The location in the Saransk urban district is the first record of Q. rubra outside cultivation. Notably, Silaeva et al. (2010) [19] did not indicate this species even as a cultivated plant in Mordovia, although in the Botanical Garden of the Mordovia State University it has a tendency towards escaping into the wild with consequent dispersal.

\section{Reynoutria $\times$ bohemica Chrtek \& Chrtková (Polygonaceae)}

Locations: 1) Russia, Republic of Mordovia, Saransk urban district, 54.190240 ${ }^{\circ}$, $45.125102^{\circ}$ E, Author ID: obruchnikova99, 14.06.2020, iNaturalist-observation: https:/www.inaturalist.org/observations/49704346; 2) Russia, Republic of Mordovia, Saransk urban district, 54.209470 ${ }^{\circ}$ N, 45.177662 ${ }^{\circ}$ E, T.B. Silaeva, 05.09.2020, iNaturalist-observation: https:/www.inaturalist.org/observations/58626322; 3) Russia, Republic of Mordovia, Saransk urban district, $54.177624^{\circ} \mathrm{N}, 45.133068^{\circ}$ E, E.S. Fedasheva, 04.08.2020, iNaturalist-observation: https://www.inaturalist.org/observations/55415186.

Note: Silaeva et al. (2010) [19] did not indicate this hybrid as a cultivated plant in Mordovia. Here, we found it for the first time outside cultivation in the Saransk urban district. Nevertheless, new records of $R$. × bohemica are possible in the Republic of Mordovia.

\section{Stachys byzantina K.Koch (Lamiaceae)}

Locations: 1) Russia, Republic of Mordovia, Saransk urban district, $54.210102^{\circ} \mathrm{N}, 45.124374^{\circ} \mathrm{E}$, Author ID: regina_kadikina, 29.06.2020, iNaturalist-observation: https://www.inaturalist.org/observations/51373414.

Note: This alien species is widely cultivated in lawns, flower-gardens, backyards and cemeteries, despite S. byzantina not being indicated in Silaeva et al. (2010) [19], even as a cultivated plant. We suspect there are new records of this ornamental species outside cultivation, primarily in abandoned backyards, cemeteries and other disturbed and ruderal habitats.

\section{Symphytum $\times$ uplandicum Nyman (Boraginaceae)}

Locations: 1) Russia, Republic of Mordovia, Ichalki district, $54.697351^{\circ} \mathrm{N}, 45.251351^{\circ}$ E, M.A. Tyapukhina, 11.06.2020, iNaturalist-observation: https://www.inaturalist.org/observations/49809437.

Note: This location is the first discovery of the species in Mordovia [19]. In future, new records are possible among ruderal habitats.

\section{Achillea leptophylla M.Bieb. (Asteraceae)}

Locations: 1) Russia, Republic of Mordovia, Saransk urban district, $54.174131^{\circ} \mathrm{N}, 45.206955^{\circ}$ E, E.S. Fedasheva, 01.07.2020, iNaturalist-observation: https://www.inaturalist.org/observations/51583236.

Note: This species was not indicated for Mordovia in Silaeva et al. (2010) [19]. Data on the presence of $A$. leptophylla in Mordovia appeared on the iNaturalist platform on 01.07.2020, although the first record of this species in Mordovia had been published earlier [23]. Perhaps $A$. leptophylla arrived in the Republic of Mordovia together with lawn grass seeds. 


\section{Amaranthus cruentus L. (Amaranthaceae)}

Locations: 1) Russia, Republic of Mordovia, Saransk urban district, $54.191292^{\circ}$ N, $45.206754^{\circ}$ E, T.B. Silaeva, 12.09.2020, iNaturalist-observation: https://www.inaturalist.org/observations/60409926; 2) Russia, Republic of Mordovia, Saransk urban district, $54.131276^{\circ}$ N, $45.140602^{\circ}$ E, T.B. Silaeva, 26.09.2020, iNaturalist-observation: https://www.inaturalist.org/observations/60872556.

Note: Amaranthus cruentus was not indicated for Mordovia by Silaeva et al. (2010) [19]. Although on iNaturalist platform, data about this species in Mordovia appeared on 22.09.2020 and 27.09.2020, Khapugin (2013) [7] had earlier published for the first time that it was present in the region. We suspect that new records are possible among disturbed habitats, primarily in the human settlements and cemeteries of the Republic of Mordovia.

\section{Cruciata laevipes Opiz (Rubiaceae)}

Locations: 1) Russia, Republic of Mordovia, Saransk urban district, $54.061790^{\circ} \mathrm{N}, 45.089571^{\circ} \mathrm{E}$, T.B. Silaeva, 30.08.2020, iNaturalist-observation: https://www.inaturalist.org/observations/58053917.

Note: This species was not mentioned for Mordovia by Silaeva et al. (2010) [19]. Despite data about $C$. laevipes in the region having appeared on the iNaturalist platform on 30.08.2020, information about the presence of this species in Mordovia was published for the first time earlier on the basis of its being found on the railways in the Lyambir district of the Republic of Mordovia [21]. New records of this species are possible along the railways in Mordovia.

\section{Euphorbia cyparissias L. (Euphorbiaceae)}

Locations: 1) Russia, Republic of Mordovia, Romodanovo district, $54.412291^{\circ} \mathrm{N}, 45.184833^{\circ} \mathrm{E}$, A.A. Khapugin, 20.06.2012, iNaturalist-observation: https://www.inaturalist.org/observations/39528825.

Note: In Silaeva et al. (2010) [19], E. cyparissias was mentioning with a question mark ('?'), as a species of which the presence in the region was not confirmed. The iNaturalist observation presented by us refers to the location, which was indicated as a new species only for the flora of the Romodanovo district [7]. Actually, this find is a new species for the vascular plant flora of the Republic of Mordovia. We expect an increase in the number of records of this species in the future, mainly in human settlements and in cemeteries and their vicinities.

\section{Silene wolgensis (Hornem.) Otth (Caryophyllaceae)}

Locations: 1) Russia, Republic of Mordovia, Saransk urban district, $54.174787^{\circ} \mathrm{N}, 45.210366^{\circ}$ E, T.B. Silaeva, 07.07.2019, iNaturalist-observation: https://www.inaturalist.org/observations/51693238; 2) Russia, Republic of Mordovia, Saransk urban district, $54.192401^{\circ}$ N, $45.124592^{\circ}$ E, E.S. Fedasheva, 28.06.2020, iNaturalistobservation: https://www.inaturalist.org/observations/51225501.

Note: The species was not indicated for the Republic of Mordovia by Silaeva et al. (2010) [19]. Data on the presence of $S$. wolgensis in the region appeared on the iNaturalist platform on 02.07.2020, although the first find of this species in the Republic of Mordovia had been published previously [23]. We assume that it was introduced into Mordovia along with lawn grass seeds.

\section{Conclusions}

Thus, taking into account the data we obtained, and previous publications [12, 19, 22, 23], the vascular plant flora of the Republic of Mordovia is represented by 1464 species. Additionally, we have supplemented and/or confirmed by photo-observations the distribution of the five species 
(Silene wolgensis, Amaranthus cruentus, Cruciata laevipes, Euphorbia cyparissias, Achillea leptophylla) found in Mordovia after publication of Silaeva et al. (2010) [19]. For the future, we suggest performing special research in relation to both diversity and distribution in Mordovia on the following pairs of plant species: Nonea pulla / Nonea rossica and Erigeron annuus / Erigeron strigosus. Most of the new species found are aliens. This indicates the active dispersal of weeds (Erigeron strigosus, Oenothera villosa, Digitaria sanguinalis, Cruciata laevipes, Silene wolgensis, Achillea leptophylla) and the escape into the wild (naturalization outside cultivation) of cultivated plants (Medicago $\times$ varia, Dianthus chinensis, Symphytum $\times$ uplandicum, Lamprocapnos spectabilis, Petunia $\times$ atkinsiana, Oenothera villosa, Parthenocissus inserta, Reynoutria $\times$ bohemica, Eschscholzia californica, Quercus rubra, Lysimachia punctata, Acer ginnala, Stachys byzantina, Amaranthus cruentus, and Euphorbia cyparissias).

That the present data were obtained during a single field season in Mordovia using the iNaturalist platform allows us to strongly recommend this citizen science platform as one of the leading tools for biodiversity research not only with professional specialists, but also amateur naturalists. However, we need to say that in Russia there is a lack of Russian-language guidelines to apply the iNaturalist platform to a methodologically correct study of biodiversity. Therefore, there is an urgent need to develop this methodology.

Acknowledgements: Authors are indebted to the iNaturalist platform community, especially experts whose voluntary contribution has allowed the identification of the observations discussed in this article up to Research Grade level. We are especially grateful to Dr.Sc. Alexey P. Seregin (Moscow State University, Russia), a moderator and mastermind of the iNaturalist project "Flora of Russia", for his valuable comments and advice on the initial stage of the manuscript preparation, which allowed us to improve the quality of this work. The present study was supported by the grant of FEWZ-2020-0009 from the Ministry of Education and Science of the Russian Federation.

\section{REFERENCES}

1. Bartók, A., Brădeanu, A.N., Bobocea, M.M., Goja, P.L., 2019, Rediscovery and a new record of the elusive and enigmatic Hammarbya paludosa (L.) Kuntze (Orchidaceae) in Romania, Contrib.Bot., 54: 99-106. DOI: 10.24193/Contrib.Bot.54.7.

2. Besi, E.E., Nikong, D., Pungga, R.S., Go, R., 2020, Wild orchid diversity of highland forest in the Heart of Borneo: Long Banga and Tama Abu, Sarawak, Nature Conservation Research, 5(Suppl.1): 125-135. DOI: 10.24189/ncr.2020.048.

3. Coritico, F.P., Amoroso, V.B., 2020, Threatened lycophytes and ferns in four Protected Areas of Mindanao, Philippines, Nature Conservation Research, 5(4): 78-88. DOI: 10.24189/ncr.2020.061.

4. Esanov, H.K., 2016, New plant species in the flora of Bukhara oasis, Turczaninowia, 19(2): 77-81, [in Russian].

5. Fateryga, V.V., Fateryga, A.V., 2019, Additions to the vascular plant flora of the Karadag State Nature Reserve (Crimea), Nature Conservation Research, 4(2): 67-82. DOI: 10.24189/ncr.2019.017, [in Russian].

6. Grishutkin, O.G., Boychuk, M.A., Grishutkina, G.A., Rukavishnikova, V.V., 2020, Check-list and ecology of Sphagnum mosses (Sphagnaceae) in the Republic of Mordovia (Russia), Nature Conservation Research, 5(3), 114-133. DOI: 10.24189/ncr.2020.038 [In Russian].

7. Khapugin, A.A., 2013, Vascular plants of Romodanovo district of the Republic of Mordovia (a synopsis), Saransk; Pushta, [in Russian].

8. Kobiv, Yu., Prokopiv, A., 2018, Bili Skeli limestone cliffs as an important hotspot of plant diversity in the Chyvchyny Mountains (Ukrainian Carpathians), Contrib.Bot., 53: 19-26.

DOI: 10.24193/Contrib.Bot.53.2.

9. Kuzmin, I.V., Khapugin, A.A., 2020, A grid mapping scheme for the flora of Tyumen city: a case study for an invasive and a synanthropic plant species. In: Problems of studying the vegetation cover of Siberia: Proceedings 


\section{A.A. KHAPUGIN, T.B. SILAEVA, E.S. FEDASHEVA, M.A. TYAPUKHINA, A.S. GURYANOVA, V.I. SHLYAPKINA, I.G. ESINA, A.N. KOCHETKOVA, D.A. KONUSOVA, N.S. MUKLETSOVA, E.S. PANKOVA, A.A. TIMOFEEVA}

of the VII International conference, dedicated to the 135th anniversary of the P.N. Krylov Herbarium of Tomsk State University and 170 anniversary of P.N. Krylov (Tomsk, September 28-30): 70-72. Tomsk. DOI: 10.17223/978-5-94621-927-3-2020-22.

10. Maevskiy, P.F., 2006, Flora of the Central Part of European Russia, $10^{\text {th }}$ ed., Moscow, KMK Scientific Press Ltd., [in Russian].

11. Maevskiy, P.F., 2014, Flora of the Central Part of European Russia, $11^{\text {th }}$ ed., Moscow, KMK Scientific Press Ltd., [in Russian].

12. Pismarkina, E.V., Chkalov, A.V., Silaeva, T.B., Pakina, D.V., 2020, Floristic records in the Republic of Mordovia and Penza province, Bulletin of Moscow Society of Naturalists, 125(3): 49-51, [in Russian].

13. POWO, 2020, Plants of the World Online, facilitated by the Royal Botanic Gardens, http://www.plantsoftheworldonline.org. Accessed 17 November 2020.

14. Roleček, J., Dřevojan, P., Šmarda, P., 2019, First record of Festuca amethystina L. from the Transylvanian basin (Romania), Contrib.Bot., 54: 91-97. DOI: 10.24193/Contrib.Bot.54.6.

15. Rosenberg, M.S., 2018, New record and range extension of the fiddler crab Uca princeps (Smith, 1870) (Brachyura, Ocypodidae) from California, USA, Journal of Crustacean Biology, 38(6): 823-824. DOI: 10.1093/jcbiol/ruy071.

16. Schuette, S., Folk, R., Cantley, J., Martine, C., 2018, The hidden Heuchera: How science Twitter uncovered a globally imperiled species in Pennsylvania, USA, PhytoKeys, 96: 87-97. DOI: 10.3897/phytokeys.96.23667.

17. Seregin, A.P., Bochkov, D.A., Shner, J.V., Garin, E.V., Mayorov, S.R., Goliakov, P.V., Bolshakov, B.V., Prokhorov, V.E., Mallaliev, M.M., Vinogradov, G.M., Ebel, A.L., Kashirina, E.S., Biryukova, O.V., Kuryakova, O.P., Mirvoda, S.V., Khimin, A.N., Murtazaliev, R.A., Zelenkova, V.N., Dudov, S.V., Gorbunova, M.S., Gerasimov, S.V., Ebel, A.L., Travkin, V.P., Chernyagina, O.A., Razina, E.A., Zyryanov, A.P., Tretyakova, D.V., Lednev, S.A., Teploukhov, V.Y., Kuzmenckin, D.V., Krivosheev, M.M., Popov, E.S., Sultanov, R.R., Basov, Y.M., Dudova, K.V., Tishin, D.V., Yakovlev, A.A., Danilevsky, Y.V., Pospelov, I.N., Kandaurova, A.N., Kutueva, S.B., Yumagulov, D.A., Samodurow, K.V., Smirnova, L.Y., Bury, U.V., Yusupov, V.E., Epikhin, D.V., Repina, T.G., Boginsky, E.I., Dubynin, A.V., Korobkov, A.V., Nesterkova, D.V., Poluyanov, A.V., Danilin, A.V., Efremov, A.N., Pozhidaeva, L.V., Verkhozina, A.V., Postnikov, Y.A., Linnik, E.A., Kobuzeva, I.A., Prokopenko, S.V., Shumikhina, E.A., Kushunina, M.A., Kuzmin, I.V., Rasran, L.M., Sukhova, D.V., Popov, A.V, 2020a, Flora of Russia on iNaturalist: big data on biodiversity of a big country, Zhurnal Obshchei Biologii, 81(3): 223-233. DOI: 10.31857/S0044459620030070, [in Russian].

18. Seregin, A.P., Bochkov, D.A., Shner, J.V., Garin, E.V., Pospelov, I.N., Prokhorov, V.E., Golyakov, P.V., Mayorov, S.R., Svirin, S.A., Khimin, A.N., Gorbunova, M.S., Kashirina, E.S., Kuryakova, O.P., Bolshakov, B.V., Ebel, A.L., Khapugin, A.A., Mallaliev, M.M., Mirvoda, S.V., Lednev, S.A., Nesterkova, D.V., Zelenova, N.P., Nesterova, S.A., Zelenkova, V.N., Vinogradov, G.M., Biryukova, O.V., Verkhozina, A.V., Zyrianov, A.P., Gerasimov, S.V., Murtazaliev, R.A., Basov, Y.M., Marchenkova, K.Yu., Vladimirov, D.R., Safina, D.B., Dudov, S.V., Degtyarev, N.I., Tretyakova, D.V., Chimitov, D.G., Sklyar, E.A., Kandaurova, A.N., Bogdanovich, S.A., Dubynin, A.V., Chernyagina, O.A., Lebedev, A.V., Knyazev, M.S., Mitjushina, I.Yu., Filippova, N.V., Dudova, K.V., Kuzmin, I.V., Svetasheva, T.Yu., Zakharov, V.P., Travkin, V.P., Magazov, Y.O., Teploukhov, V.Yu., Efremov, A.N., Deineko, O.V., Stepanov, V.V., Popov, E.S., Kuzmenckin, D.V., Strus, T.L., Zarubo, T.V., Romanov, K.V., Ebel, A.L., Tishin, D.V., Arkhipov, V.Yu., Korotkov, V.N., Kutueva, S.B., Gostev, V.V., Krivosheev, M.M., Gamova, N.S., Belova, V.A., Kosterin, O.E., Prokopenko, S.V., Sultanov, R.R., Kobuzeva, I.A., Dorofeev, N.V., Yakovlev, A.A., Danilevsky, Y.V., Zolotukhina, I.B., Yumagulov, D.A., Glazunov, V.A., Bakutov, V.A., Danilin, A.V., Pavlov, I.V., Pushay, E.S., Tikhonova, E.V., Samodurov, K.V., Epikhin, D.V., Silaeva, T.B., Pyak, A.I., Fedorova, Y.A., Samarin, E.S., Shilov, D.S., Borodulina, V.P., Kropocheva, E.V., Kosenkov, G.L., Bury, U.V., Mitroshenkova, A.E., Karpenko, T.A., Osmanov, R.M., Kozlova, M.V., Gavrilova, T.M., Senator, S.A., Khomutovskiy, M.I., Borovichev, E.A., Filippov, I.V., Ponomarenko, S.V., Shumikhina, E.A., Lyskov, D.F., Belyakov, E.A., Kozhin, M.N., Poryadin, L.S., Leostrin, A.V., 2020b, "Flora of Russia" on iNaturalist: a dataset, Biodiversity Data Journal, 8, e59249. DOI: 10.3897/BDJ.8.e59249.

19. Silaeva, T.B., Kiryukhin, I.V., Chugunov, G.G., Levin, V.K., Mayorov, S.R., Pismarkina, E.V., Ageeva, A.M., Vargot, E.V., 2010, Vascular plants of the Republic of Mordovia (synopsis of flora), Saransk, Mordovia State University, [in Russian]. 
20. Silaeva, T.B., Chugunov, G.G., Kiryukhin, I.V., Ageeva, A.M., Vargot, E.V., Grishutkina, G.A., Khapugin, A.A., 2011, Flora of the National Park «Smolny». Mosses and vascular plants: annotated list of species, Moscow, Commission of RAS for the Conservation of Biodiversity, [in Russian].

21. Silaeva, T.B., Ageeva, A.M., Ivashina, A.A., Khapugin, A.A., Tokarev, D.V., Vargot, E.V., 2016, Floristic records in the north-west of the Volga Upland, Bulletin of Moscow Society of Naturalists, 121(3): 63-66, [in Russian].

22. Silaeva, T.B., Pismarkina, E.V., Ageeva, A.M., Ershkova, E.V., Kiryukhin, I.V., Khapugin, A.A., Chugunov, G.G., 2019, Materials for the flora of the Republic of Mordovia. In: Structure, dynamics and functioning of natural-social-production systems: science and practice: 46-55. Saransk, [in Russian].

23. Silaeva, T.B., Ageeva, A.M., Shkulev, A.A., Fedasheva, E.S., 2020, Records in the Republic of Mordovia and Nizhny Novgorod Province in 2019, Bulletin of Moscow Society of Naturalists, 125(3): 47-48, [in Russian].

24. Teteryuk, L.V., Degteva, S.V., Kanev, V.A., Valuyskikh, O.E., Teteryuk, B.Yu., Kulyugina, E.E., 2020, Rare and protected vascular plants in Yugyd va National Park (Russia), Nature Conservation Research, 5(4): 16-29. DOI: $10.24189 /$ ncr.2020.051, [in Russian].

25. Ueda, K., 2020, iNaturalist Research-grade Observations. iNaturalist.org. Occurrence dataset, https://doi.org/10.15468/ab3s5x. Accessed via GBIF.org on 16 November 2020.

26. Vargot, E.V., Khapugin, A.A., Chugunov, G.G., Grishutkin, O.G., 2016a, Vascular plants of the Mordovia State Nature Reserve (an annotated species list). Moscow, Commission of RAS for the Conservation of Biological Diversity, [in Russian].

27. Vargot, E.V., Shcherbakov, A.V., Bolotova, Ya.V., Uotila, P., 2016b, Current distribution and conservation of Najas tenuissima (Hydrocharitaceae), Nature Conservation Research, 1(3): 2-10. DOI: 10.24189/ncr.2016.022.

28. Verkhozina, A.V., Chernysheva, O.A., Ebel, A.L., Erst, A.S., Dorofeev, N.V., Dorofeyev, V.I., Grebenjuk, A.V., Grigorjevskaja, A.Y., Guseinova, Z.A., Ivanova, A.V., Khapugin, A.A., Korolyuk, A.Y., Korznikov, K.A., Kuzmin, I.V., Mallaliev, M.M., Murashko, V.V., Murtazaliev, R.A., Popova, K.B., Safronova, I.N., Saksonov, S.V., Sarajeva, L.I., Senator, S.A., Troshkina, V.I., Vasjukov, V.M., Wang, W., Xiang, K., Zibzeev, E.G., Zolotov, D.V., Zykova, E.Y., Krivenko, D.A., 2020, Findings to the flora of Russia and adjacent countries: New national and regional vascular plant records, 2, Botanica Pacifica, 9(1): 139-154. DOI: 10.17581/BP.2020.09115.

29. Yamashkin, A.A., 2012, Geographical atlas of the Republic of Mordovia, Saransk, Publisher of the Mordovia State University, [in Russian].

\section{COMPLETĂRI LA FLORA PLANTELOR VASCULARE DIN REPUBLICA MORDOVIA (RUSIA): CONTRIBUȚII LA PLATFORMA iNATURALIST}

\section{(Rezumat)}

(Re)verificarea datelor din iNaturalist cu privire la Republica Mordovia (Rusia Europeană) ne-a permis să identificăm 16 specii de plante vasculare, considerate a fi taxoni noi pentru flora acestei regiuni, după Silaeva et al. (2010). Aceste specii sunt Nonea rossica, Erigeron strigosus, Medicago $\times$ varia, Dianthus chinensis, Symphytum $\times$ uplandicum, Lamprocapnos spectabilis, Petunia $\times$ atkinsiana, Oenothera villosa, Parthenocissus inserta, Reynoutria $\times$ bohemica, Eschscholzia californica, Quercus rubra, Digitaria sanguinalis, Lysimachia punctata, Acer ginnala și Stachys byzantina. În plus, prezentăm date noi despre distribuția a cinci specii (Silene wolgensis, Amaranthus cruentus, Cruciata laevipes, Euphorbia cyparissias și Achillea leptophylla) găsite în Republica Mordovia după apariția publicației Silaeva et al. (2010). Majoritatea speciilor luate în studiu sunt plante alohtone ajunse în Mordovia accidental sau plante cultivate scăpate din cultură. Luând în considerare speciile nou descoperite, flora vasculară a Republicii Mordavia cuprinde, actualmente, 1464 specii. În acest studiu s-a subliniat încă o dată relevanța și fezabilitatea utilizării platformei iNaturalist, ca un instrument eficient pentru studierea și monitorizarea biodiversității locale și naționale. 